\title{
CORANTES MARCADORES DE COMBUSTÍVEIS: LEGISLAÇÃO E MÉTODOS ANALÍTICOS PARA DETECÇÃO
}

\author{
Magno Aparecido Gonçalves Trindade \\ Faculdade de Ciências Exatas e Tecnologia, Universidade Federal da Grande Dourados, Rodovia Dourados-Itahum, km 12, \\ 79804-970 Dourados - MS, Brasil \\ Nelson Ramos Stradiotto e Maria Valnice Boldrin Zanoni * \\ Departamento de Química Analítica, Instituto de Química, Universidade Estadual de São Paulo, 14800-900 Araraquara - SP, Brasil
}

Recebido em 9/8/10; aceito em 11/3/11; publicado na web em 5/5/11

\begin{abstract}
DYES MARKERS OF FUELS: LEGISLATION AND ANALYTICAL METHODS FOR DETECTION. The use of dyes in the commercialization of fuel is usually associated with protection of the source and destination. It is used as "markers" to identify and guarantee the identity of the specific product of a particular manufacturer to discourage theft, tampering and disclosure of the quality of solvent or fuel. This work presents a critical analysis on the state of the art about the available analytical methods for identification and quantification of dyes used as markers of solvents and fuels, as well as evaluation of the physical-chemical staining and laws surrounding their use and commercialization.
\end{abstract}

Keywords: dyes markers; fuels; analytical methods.

\section{CONSIDERAÇÕES GERAIS}

O segmento de petróleo introduziu nos últimos anos novas regras de consumo de combustíveis no mercado brasileiro, as quais, juntamente com restrições ambientais mais rígidas, exigiram produtos com maior qualidade para atender à competitividade do mercado nacional.

Os programas destinados à melhoria da qualidade dos combustíveis no Brasil espelham-se, sobretudo, naqueles lançados na União Europeia e nos Estados Unidos, os quais prevêem, dentre várias medidas, o desenvolvimento de combustíveis cada vez mais nobres com baixíssimos teores de enxofre e diferenças significativas de preços. ${ }^{1-4}$ A especificação dos combustíveis com alta qualidade tem impacto direto no mercado e no meio ambiente, cuja produção deve focar o bom funcionamento dos motores, como também proporcionar garantia de saúde aos manipuladores, contribuir para a preservação do ambiente e, ainda, evitar práticas de adulteração e sonegação fiscal. Isso contribui sobremaneira para o avanço na área, o que requer investimentos em tecnologia e desenvolvimento de veículos com performance ambientalmente compatíveis (menos poluentes).

A partir da década de 70, observa-se que o controle de qualidade do petróleo e de seus derivados recebe destaque mundial, cujo melhoramento visa, principalmente, diminuir a poluição causada pelos gases de escape dos veículos. A emissão de alguns poluentes, como o monóxido de carbono, os hidrocarbonetos não queimados e os óxidos de nitrogênio, tem merecido regras rígida das entidades governamentais de proteção ao meio ambiente. Essas regras, cada vez mais severas, obrigaram os fabricantes de veículos a aprimorarem os projetos de seus motores e adotarem eficientes conversores catalíticos, a fim de reduzir a emissão de poluentes na atmosfera. ${ }^{5}$, ${ }^{6}$ No entanto, a presença de compostos de enxofre ainda é relevante nestes combustíveis, o que demanda significativo empenho por parte dos produtores e das entidades reguladoras para atender à legislação ambiental.

*e-mail: boldrinv@iq.unesp.br
O uso de marcadores químicos e/ou corantes adicionados aos combustíveis é uma prática importante das distribuidoras para o controle de qualidade de seus produtos. Os laboratórios móveis são, muitas vezes, utilizados para monitorar periodicamente a qualidade e a origem dos combustíveis disponíveis nos postos de distribuição. Além disso, a Agência Nacional do Petróleo, Gás Natural e Biocombustíveis (ANP) requer de todas as distribuidoras um boletim de conformidade (para cada fornecimento), que ateste a qualidade do combustível entregue nos postos sob seu domínio, cujo procedimento propicia melhoria significativa na qualidade desses produtos. De forma semelhante ao que ocorre em países desenvolvidos, o uso de marcadores químicos e/ou corantes em combustíveis e/ou solventes, no Brasil, tem inibido, de forma eficiente, a adulteração e, consequentemente, permitido maior controle na comercialização. Hoje, grande parte dos postos de distribuição de combustíveis no país é rigorosamente monitorada de acordo com as diretrizes da política de qualidade de produtos da ANP. Essas diretrizes protegem o interesse do consumidor, garantindo derivados de petróleo, gás natural e etanol combustível adequados ao uso, além de proporcionar à sociedade boa qualidade de vida ocasionada pela diminuição dos problemas ambientais. Ademais, este procedimento confere maior credibilidade à qualidade dos produtos consumidos no país e promove a livre concorrência para os produtos com especificações fielmente rotuladas. ${ }^{1,4}$

No caso do óleo diesel, estas especificações são ainda mais importantes, por se tratar de um dos derivados do petróleo mais crítico em termos ambientais. O diesel, vendido nas grandes cidades, deveria conter menos enxofre que aquele das áreas rurais e pequenas cidades, para que houvesse diminuição da poluição urbana, que em grandes metrópoles envolve usualmente maior concentração de veículos. O óleo diesel interior (S1800), por exemplo, contém um corante vermelho que é adicionado pela própria refinaria, sendo exclusivamente usado em regiões fora dos grandes centros. Outra característica inerente a este combustível é o teor de enxofre, no qual o limite máximo permitido pela ANP é de $2000 \mathrm{mg} \mathrm{kg}^{-1}$ de amostra, diferentemente do óleo diesel metropolitano - conhecido como S50 e 
S500, em que os teores de enxofre são, respectivamente, de 50 e 500 $\mathrm{mg} \mathrm{kg}{ }^{-1}$ de amostra. Neste contexto, o uso de corantes marcadores com características específicas é de fundamental importância para o controle da qualidade pelas Agências Reguladoras.

Devido ao expressivo uso de etanol combustível na gasolina, a demanda por marcadores aplicáveis a este solvente também é um desafio, principalmente, ao ser considerado que, de acordo com estimativas recentes, milhões de litros desse combustível podem estar sendo comercializados irregularmente. Os meios de comunicação, por exemplo, veiculam que alguns produtores, distribuidores e revendedores infringem a lei ao venderem combustíveis de forma ilegal, sonegarem impostos, e também ao adulterá-los com adição de solventes ou, no caso do etanol, com adição de água. A utilização do combustível altamente hidratado provoca perda de potência, maior consumo e corrosão nos automóveis. Assim, o uso de marcadores químicos e/ou corantes tornase uma prática comum nesse mercado, pois estes podem ser utilizados tanto para combater fraudes, sonegação fiscal e adulteração, quanto para assegurar a procedência e qualidade do produto..$^{1,7-9}$

O uso de marcadores também é relevante nos casos em que se observam diferenças de tratamentos fiscais a combustíveis e derivados de petróleo com finalidade específica. Em alguns países, por exemplo, os derivados do petróleo, destinados a segmentos como pesca, mineração, geração de energia elétrica, aquecimento de residências, agricultura, transportes e lazer, podem ter subsídios importantes que, por sua vez, requerem diferenciação específica para o melhor controle da qualidade. Isto tem aumentado, consideravelmente, o mercado de marcadores químicos e biológicos, traçantes e corantes - que tem o comércio controlado por grandes companhias - destinados à marcação de produtos petrolíferos. Esse controle está em conformidade com a expansão de um mercado que inclui desde países da África, que lutam contra o contrabando de derivados de petróleo, até países da União Europeia e os Estados Unidos, que usualmente fornecem subsídios a produtos como óleo para aquecimento de residências (heating oil) e diesel a ser usado fora de rodovias (off highway diesel), como, por exemplo, na agricultura. , $^{1,7}$

É importante considerar que os combustíveis para consumo são constituídos por misturas de diversos componentes obtidos em diferentes processos de refino. Além disso, recebem a adição de diversos outros compostos químicos com finalidades específicas, como: antioxidantes, antidetonantes, detergentes, anticongelantes, desativadores de metais, corantes, marcadores, entre outros, os quais interferem na qualidade e na finalidade do combustível. Portanto, precisam ser diferenciados para manter a sua individualidade e as características peculiares de cada produto final, o que leva ao uso de marcadores e/ou corantes. Isto requer métodos analíticos específicos para identificação e quantificação destes compostos, o que não é um trabalho trivial, ao considerar que, usualmente, o combustível é uma amostra complexa e os corantes marcadores possuem estruturas químicas e propriedades físico-químicas diferenciadas. Ademais, esses corantes, contendo grupos cromóforos, do tipo azo, antraquinona, nitro e aminas substituídas, estão presentes nestas amostras em baixos níveis de concentração.

Nesse contexto, no presente trabalho são apresentados alguns fatores importantes para se entender o processo de marcação de combustíveis e as legislações que envolvem seu uso em diversos países. Também será realizada uma análise crítica dos métodos analíticos disponíveis na literatura, até o presente momento, para determinação destes marcadores em amostras de combustíveis, enfatizando os marcadores baseados em corantes.

\section{MARCADORES USADOS EM COMBUSTÍVEIS}

A utilização de marcadores não é um procedimento exclusivo de combustíveis. Seu uso é abrangente e está disseminado em vários segmentos do cotidiano da sociedade, como, alimentação, bebidas, vestuário, etc., todos utilizados dentro de um mesmo conceito, marcar para garantir qualidade, evitar fraudes, proteger marcas, entre outros interesses comerciais e ambientais. Na área de combustíveis, marcadores são definidos pela ANP como substâncias que, quando adicionadas a solventes ou a derivados do petróleo, não alteram suas características físico-químicas, como também não interferem no grau de segurança durante o manuseio e o uso dos mesmos e que possam ser identificados segundo métodos analíticos específicos. ${ }^{3}$

De acordo com o Regulamento Técnico da ANP (Portaria n. 274, de 1/11/2001), ${ }^{3}$ é obrigatória a adição de um marcador em concentração não superior a $1,00 \mathrm{mg} \mathrm{L}^{-1}(1,00 \mathrm{ppm})$ a solventes e derivados do petróleo eventualmente indicados por ela. Entretanto, nos dias atuais, a utilização de marcadores não é específica para esses produtos, sendo disseminada em vários segmentos da indústria petrolífera. São também chamados de "marcadores invisíveis" e usados como substâncias características de cada distribuidora. Portanto, possuem fórmulas e informações técnicas protegidas por segredo industrial do fabricante, sendo estas informações abertas apenas mediante contrato de confidencialidade entre fornecedores e usuários.

Os produtos marcados pela distribuidora com estes marcadores invisíveis são também usados para identificação de solventes provenientes de diferentes frações do processamento do petróleo bruto, como frações de refinarias e/ou indústrias petroquímicas, de querosene comum, querosene de aviação, alguns tipos de gasolina e o óleo diesel comum. ${ }^{3,4}$ A ausência ou modificação da concentração do marcador de um solvente, por exemplo, indica que o combustível foi adulterado e sua utilização é indevida. A diluição do marcador na amostra pode coibir a adição de solventes inadequados e mais baratos à gasolina. Isto é um trabalho relevante de identificação, uma vez que estes solventes não alteram a composição química do combustível, o que dificulta sua percepção visual e, consequentemente, sua detecção por métodos instrumentais menos sofisticados.

A detecção de um marcador invisível a um produto, em alguns casos, só é possível por métodos específicos adotados por cada distribuidora. Dentre estes, ressaltam-se os métodos econômicos, ou seja, aqueles que requerem apenas reações com produtos químicos específicos, cuja revelação dar-se-á pela alteração do meio ácido para básico, ou vice-versa. Ou ainda, métodos mais sofisticados, como o uso de isótopos não radioativos, técnicas cromatográficas, entre outras técnicas analíticas. ${ }^{1,4}$ É importante salientar que a literatura disponibiliza poucos trabalhos envolvendo marcadores em amostras de combustíveis, dos quais a grande maioria é protegida por patentes.

Por outro lado, em uma mesma distribuidora é possível encontrar produtos com cor diferenciada, visível ao consumidor através de filtros transparentes adaptados nos bicos das bombas, cujo sistema de marcação envolve a adição de corantes específicos. Sendo assim, apresentar-se-á, a seguir, uma análise crítica do uso de corantes como marcadores em combustíveis, como também os métodos analíticos disponíveis para detecção e quantificação em diferentes amostras.

\section{CORANTES EM COMBUSTÍVEIS}

Corantes marcadores caracterizam-se como substâncias coloridas com extensa ressonância de aromáticos, contendo grupos substituintes que não se ionizam quando adicionados aos materiais designados que, comumente, são apolares. Usualmente, são denominados "marcadores visíveis" ou "corantes marcadores", e quando adicionados aos combustíveis permitem diferenciação visual entre diferentes tipos ou qualidades dos mesmos. Como citado anteriormente, o objetivo da marcação com estes corantes vai desde a prevenção de fraudes fiscais até a proteção ambiental, como, por exemplo, a diferenciação de combustíveis contendo altos teores de enxofre. ${ }^{4,6-9}$ 
Estes compostos são necessariamente sintéticos de natureza orgânica e com caráter não iônico, cuja classificação segue as normas estabelecidas pelo Colour IndeX. Neste caso, o corante é catalogado de acordo com suas características e aplicações e atende a um padrão geral com a seguinte terminologia "solvente + cor + número", ou seja, tipo de corante, cor e tonalidade, como, por exemplo, Solvente Vermelho 24. Esta denominação corante solvente, usualmente, se dá por causa de sua solubilidade e da proposta de utilização. Estes corantes são usados para colorir não apenas solventes do tipo hidrocarbonetos, mas também outros derivados do petróleo, como, ceras, lubrificantes, plásticos, dentre outros materiais de natureza apolar. ${ }^{10,11}$ A Tabela 1 apresenta uma compilação das estruturas químicas correspondentes a estes corantes do tipo solvente.

Corantes do tipo solvente possuem, em sua estrutura básica, grupos cromóforos responsáveis pela coloração, comumente, aqueles com tons de cor vermelha e amarela, portadores de grupos azo, enquanto os com cor verde e azul são geralmente portadores do grupo antraquinona (Tabela 1). Assim como em outros seguimentos de corantes empregados nas indústrias têxtil, cosmética, farmacêutica e alimentícia, os corantes portadores de grupos azo e antraquinonas, não surpreendentemente, são os mais empregados no segmento de coloração de combustíveis.

Ao contrário do que se busca nas indústrias têxtil, cosmética, fotográfica, farmacêutica, papeleira e alimentícia, em que o processo de tintura é um dos fatores fundamentais para o sucesso comercial de seus produtos, o uso de corantes na indústria de combustíveis usualmente não está relacionado a apelos estéticos ou ao melhoramento na performance do combustível. ${ }^{12,13}$ Os corantes são usados nestas matrizes particularmente para identificar tipos específicos de combustíveis para fins de controle e fiscalização do fabricante ou das instituições responsáveis pelo controle da procedência e/ ou destino do combustível gerado. ${ }^{1-10,14} \mathrm{Na}$ literatura encontram-se diversos exemplos típicos de aplicação de corantes relacionados aos combustíveis, como a utilização de corantes como "marcadores" para identificar gasolinas aditivadas - o que garante a identidade do produto específico de determinado fabricante que usa o corante -, desencorajando adulterações e, ao mesmo tempo, divulgando a qualidade do seu produto.

Como citado anteriormente, os corantes, usados para adição aos combustíveis, normalmente, são insolúveis em água e muito solúveis em hidrocarbonetos derivados do petróleo. Além disso, não devem alterar as propriedades físico-químicas dos combustíveis em que são inseridos e, particularmente, devem apresentar relativa resistência quando submetidos às técnicas usuais de remoção, protegendo a integridade do combustível e impedindo o uso inadequado de um corante facilmente detectável ou removível. Devido a essa última propriedade, apesar de o custo de fabricação do corante ser baixo, seu custo comercial geralmente é elevado, por causa das patentes que os protegem.

De modo geral, a análise das estruturas químicas dos corantes apresentados na Tabela 1 evidencia que embora estes sejam portadores de grupos azos e antraquinonas, como aqueles usados para outros fins, são diferentes dos corantes têxteis e alimentícios, devido às pequenas alterações em suas estruturas, vitais para proporcionar melhor interação com solventes apolares e ao meio ao qual são adicionados. A presença de grupos substituintes apolares e polares, acompanhados

Tabela 1. Características estruturais de alguns corantes empregados na marcação de combustíveis<smiles>[R3]c1ccc([R3])c2c1C(=O)c1c([R4])ccc([R1])c1C2=O</smiles>

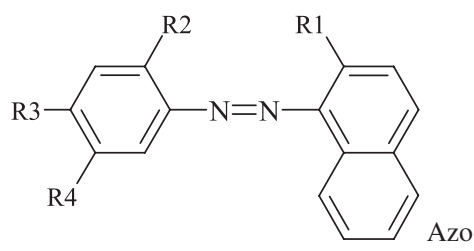

\begin{tabular}{|c|c|c|c|c|c|c|}
\hline \multirow{2}{*}{ Substâncias } & \multicolumn{6}{|c|}{ Substituições no anel } \\
\hline & $\mathbf{R}_{1}$ & $\mathbf{R}_{2}$ & $\mathbf{R}_{3}$ & $\mathbf{R}_{4}$ & $\mathbf{R}_{5}$ & $\mathbf{R}_{8}$ \\
\hline \multicolumn{7}{|l|}{ Antraquinonas } \\
\hline Solvente Azul 14 & & $\mathrm{H}$ & $\mathrm{H}$ & & $\mathrm{H}$ & $\mathrm{H}$ \\
\hline Solvente Azul 36 & & $\mathrm{H}$ & $\mathrm{H}$ & & $\mathrm{H}$ & $\mathrm{H}$ \\
\hline Solvente Azul 35 & & $\mathrm{H}$ & $\mathrm{H}$ & & $\mathrm{H}$ & $\mathrm{H}$ \\
\hline Solvente Verde 3 & & $\mathrm{H}$ & $\mathrm{H}$ & & $\mathrm{H}$ & $\mathrm{H}$ \\
\hline \multicolumn{7}{|l|}{ Azocorantes } \\
\hline Solvente Vermelho 24 & $\mathrm{OH}$ & $\mathrm{H}$ & & $\mathrm{H}$ & - & - \\
\hline Solvente Vermelho 26 & $\mathrm{OH}$ & $\mathrm{CH}_{3}$ & & $\mathrm{CH}_{3}$ & - & - \\
\hline Solvente Vermelho 164 & $\mathrm{OH}$ & $\mathrm{H}$ & & $\mathrm{H}$ & - & - \\
\hline Solvente Amarelo 14 & $\mathrm{OH}$ & $\mathrm{H}$ & $\mathrm{H}$ & $\mathrm{H}$ & - & - \\
\hline
\end{tabular}


de átomos com a propriedade de doar elétrons para o anel aromático, fornece um sistema estendido de deslocamento de elétrons $\pi$, o que permite estender a absorção de radiação na região do visível. ${ }^{15,16}$ Além disso, a presença desses grupos substituintes com átomos doadores ou aceitadores de elétrons, bem como grupos cromóforos e também grupos auxocrômicos, torna essas substâncias acessíveis para detecção por diversas técnicas analíticas.

\section{O USO DE CORANTES NO MERCADO DE COMBUSTÍVEIS}

A utilização da cor como processo marcador já foi uma propriedade de maior destaque no passado para outros fins, como, por exemplo, quando era um indicativo de eficiência de tratamento específico durante processos de refino e, em alguns casos, até mesmo da estabilidade do combustível. Nos dias atuais, o uso de substâncias, que conferem coloração aos combustíveis, tem seu uso mais específico, como, por exemplo, aqueles combustíveis aditivados que recebem um ou mais corantes para diferenciá-los dos demais. Alterações na cor dos combustíveis podem ocorrer devido à presença de contaminantes ou por causa da oxidação de compostos instáveis nela presentes (olefinas e compostos nitrogenados) ou, ainda, pela adulteração criminosa visando ampliação de lucros.

Em vários países, principalmente nos que integram a Comunidade Europeia, os distribuidores de combustíveis utilizam um sistema de marcação do diesel, o red diesel, usado especificamente para óleo de aquecimento, significativamente mais barato que os combustíveis dieseis mais pesados, os quais têm maior teor de enxofre. É importante esta diferenciação para não promover danos aos motores e ao meio ambiente. Em vista de tais problemas, as agências fiscalizadoras adotaram a adição de corantes como método de prevenção, sendo uma forma para coibir a adulteração destes tipos de combustíveis. Entre esses corantes, destacam-se os da cor vermelha, que são frequentemente portadores de grupos azo, como, por exemplo, Solvente Vermelho 19, Solvente Vermelho 24 e Solvente Vermelho 26. ${ }^{15,16}$ Entretanto, o querosene de aviação, bem como alguns óleos empregados para aquecimento têm sido marcados com um corante azul, cuja iniciativa se tornou uma forma de proteção à marca da distribuidora e aos interesses dos consumidores. ${ }^{14}$

Desde agosto de 2002, todos os países da União Europeia são obrigados a adotarem um corante em comum entre eles, o chamado "Solvente Amarelo 124" (Figura 1), cuja concentração adicionada deve ser de, aproximadamente, $6,00 \mathrm{mg} \mathrm{L}^{-1}$, a fim de que seja um marcador universal entre estes países. Este corante pode ser facilmente hidrolisado com ácidos e pode dividir o grupo acetal, responsável pela sua solubilidade em solventes apolares, transformando-o em uma forma solúvel em água. Além disso, pode ser facilmente detectado em combustíveis adulterados por diluição com solventes ou em produtos de má qualidade, a níveis baixíssimos (da ordem de $0,30 \mathrm{mg} \mathrm{L}^{-1}$ ) após a extração por procedimentos adequados. ${ }^{6}$

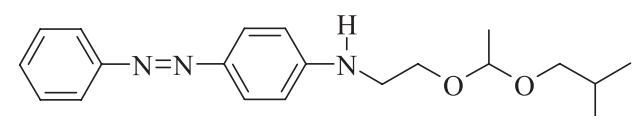

Figura 1. Fórmula estrutural do corante "Solvente Amarelo 124" $\mathrm{N}$-etil- $\mathrm{N}$ [2-(1-isobutoxietoxi)etil](4-fenilazofenil)amina

Nos Estados Unidos, a Agência de Proteção Ambiental (EPA - Environmental Protection Agency) designa o uso de um corante vermelho, o "Solvente Vermelho 26", para identificar e marcar combustíveis com altos teores de enxofre para não serem usados em áreas urbanas. Este corante é utilizado como um marcador padrão, entretanto, pode ser substituído pelo "Solvente Vermelho 164", um composto com coloração semelhante, mas com maior cadeia alquílica. Em geral, são usados em concentrações elevadas, de tal forma que possam ser detectados até mesmo quando diluídos em solventes ou em combustíveis de qualidade inferior, de modo que sua existência a um diesel de qualidade superior é indicativo de que o mesmo foi obtido indevidamente. ${ }^{11}$

No Brasil, em decorrência do contrato de confidencialidade entre os fornecedores e os órgãos que controlam e demarcam os diversos tipos de combustíveis, as informações referentes às fórmulas e demais tipos de informações relevantes para identificação destas substâncias não são reveladas. Entretanto, sabendo-se que a grande maioria dos corantes marcadores para este fim são corantes solventes portadores de grupos azo e antraquinona, acredita-se que os produtos mais nobres e caros, comercializados no Brasil, também seguem uma tendência dos mercados norte-americano e europeu, pelo uso de marcadores visuais, como os listados na Tabela 1.

Nos últimos anos, adotou-se um sistema de marcação do etanol combustível, ${ }^{2}$ cuja finalidade é garantir sua qualidade, bem como livrá-lo de fraudes de adulteração por adição de água. A adulteração do etanol combustível no Brasil tem sido maior do que a adulteração da gasolina. De acordo com boletins de qualidade emitidos pela Agência Nacional do Petróleo, Gás Natural e Biocombustíveis (ANP), este índice de não conformidade ficou ao redor de $7,0 \%$, enquanto que, para a gasolina, o mesmo índice ficou em 2,9\% e, para o diesel, em $1,7 \%$. Assim, a adição do corante no etanol combustível, teoricamente, evitaria a principal forma de adulteração, que consome milhões de reais/ano dos cofres públicos.

A determinação destes corantes por técnicas analíticas é relevante para os diversos seguimentos envolvidos. Contudo, os processos são laboriosos e raramente publicados, salvo poucas exceções. A seguir, será apresentada uma breve revisão sobre métodos de pré-tratamento de amostras de combustíveis e métodos analíticos quantitativos para determinação de uma diversidade desses compostos comercializados como marcadores.

\section{TÉCNICAS DE EXTRAÇÃO DE CORANTES EM AMOSTRAS DE COMBUSTÍVEIS}

Devido à complexidade de matrizes oriundas de combustíveis derivados do petróleo, os métodos analíticos capazes de se adequar a esta complicação são restritos, sobretudo, pela inviabilidade de determinação direta do analito nessas matrizes. Entre os maiores problemas encontrados na extração destes corantes, ressaltam-se a presença de substâncias contendo grupos sulfurados, ${ }^{17}$ nitrogenados, ${ }^{18,19}$ e oxigenados, além de produtos químicos introduzidos como aditivos, como os detergentes dispersantes, que promovem interferência significativa para a maioria dos métodos de detecção. Deste modo, são requeridos procedimentos de extração e purificação do analito nestas matrizes, exigindo, em alguns casos, etapas laboriosas, bem como o uso de solventes orgânicos tóxicos.

Os procedimentos de extração do analito neste tipo de amostra visam, além da purificação do analito de interesse, obter uma sub-fração rica do composto original, de forma que a detecção seja realizada com o mínimo de interferência. Portanto, são exigidos métodos de pré-tratamento de amostras com características físico-químicas semelhantes, pois compostos com polaridades similares, além de serem extraídos juntamente com componentes interferentes presentes nestas matrizes, podem ser coeluídos, necessitando-se de técnicas de prétratamento mais eficientes que os métodos convencionais de extração.

No desenvolvimento de métodos para isolar e concentrar analitos como os corantes, ressaltam-se os processos de extração líquido-líquido (ELL) e a extração em fase sólida (EFS). Dentre esses, a técnica de EFS oferece maiores vantagens, sendo mais empregada para sepa- 
ração de componentes interferentes em matrizes, como combustíveis, uma vez que envolve menos tempo de manipulação do analito (entre 5 e 10 min). Além disso, utiliza quantidades reduzidas de solventes orgânicos (cerca de $20 \mathrm{~mL}$ ) contra aproximadamente $500 \mathrm{~mL}$ para ELL. ${ }^{20}$ Ademais, a EFS pode ser facilmente automatizada, o que permite realizar extração de dezenas de amostras simultaneamente.

A semelhança no mecanismo de retenção com aqueles envolvidos na cromatografia líquida em coluna permite variações na espécie do material sorvente, como também possibilidades de ajustes do solvente de eluição. Na literatura, ${ }^{20-23}$ encontra-se uma variedade de publicações com diversas aplicabilidades da EFS, descrevendo métodos de extração, purificação e concentração de analitos orgânicos, além de apresentar informações sobre materiais sorventes empregados, os quais, com algumas adaptações, podem ser adaptados para o tratamento de amostras de combustíveis fósseis e seus derivados. O desenvolvimento experimental para a separação dos constituintes presentes nas amostras de combustíveis - empregando colunas de EFS que contêm um material sorvente adequado - envolve algumas etapas, sendo estas ordenadas da seguinte maneira: disponibilização dos sítios de retenção do material sorvente por ativação com um solvente adequado; obtenção de um meio semelhante ao da amostra, em que um solvente ou mistura de solventes é percolado pelo cartucho; etapa na qual o corante é concentrado através da retenção no cartucho de EFS contendo o material sorvente apropriado; etapa na qual o corante é separado dos interferentes por passagem de quantidades apropriadas de um solvente apolar ou de baixa polaridade (geralmente hexano), removendo os hidrocarbonetos e as espécies químicas interferentes menos retidas na fase estacionária e, finalmente, realiza-se a eluição do analito retido no material sorvente usando acetonitrila ou mistura de solventes orgânicos de moderada polaridade. Deste modo, a quantificação pode ser realizada pela detecção do corante em concentração e pureza já apropriadas para análise.

\section{MÉTODOS OFICIAIS PARA DETECÇÃO DE CORANTES EM COMBUSTÍVEIS}

A determinação da cor para especificações de produtos derivados do petróleo comercializados no Brasil segue procedimentos contidos nas Normas Brasileiras (NBR), Associação Brasileira de Normas Técnicas (ABNT) ou Normas da American Society for Testing and Materials (ASTM). De acordo com essas Normas, os teores desses corantes adicionados aos combustíveis são altos certamente em função do sistema de detecção da cor que é realizado por métodos visuais ou colorimétricos (Tabela 2). Esses métodos são simples e não oferecem qualquer confiabilidade analítica, principalmente, pelo fato de não diferenciarem a presença de corantes de coloração semelhante, mas estruturalmente diferentes.

Um exemplo de aplicação desse método não é recente e envolve a detecção visual da quinizarina (QNZ) em óleo diesel após procedi- mento de extração líquido-líquido. ${ }^{28}$ Neste caso, a detecção da QNZ na amostra de óleo diesel, marcada em um nível de concentração de $2,00 \mathrm{mg} \mathrm{L}^{-1}$, é realizada mediante a extração com $\mathrm{NaOH}$ após testes em diferentes proporções. A QNZ apresenta uma coloração azul-violeta na fase aquosa alcalina, cuja estabilidade de aproximadamente 30 min foi suficiente para testes visuais de detecção.

\section{MÉTODOS ALTERNATIVOS PARA DETERMINAÇÃO DE CORANTES EM COMBUSTÍVEIS}

A demanda por métodos analíticos capazes de detectar quantitativamente estes compostos tem incentivado pesquisadores a buscarem diversas alternativas para aperfeiçoar os sistemas de detecção, bem como minimizar interferências oriundas desse tipo de matriz.

No Brasil e no exterior, são comercializadas diferentes classes de óleo diesel - qualificado de acordo com o seu teor de enxofre -, de modo que a adulteração poderia ser facilmente identificável, pois o diesel interior recebe um corante vermelho, e as outras espécies não o recebem. Entretanto, em comunicações anteriores, ${ }^{14,29-31}$ divulgou-se que na Europa existe uma prática comum de remoção do corante do diesel interior para comercializá-lo como se fosse metropolitano. Esse procedimento não é facilmente detectado visualmente tão pouco pelos métodos oficiais em função da baixa concentração que, muitas vezes, é da ordem de miligramas do corante por litro de amostra. Isto tem contribuído para o desenvolvimento de diversos métodos alternativos com objetivo de determinar, a níveis de traços, uma variedade de corantes em amostras de combustíveis fósseis. Portanto, uma breve revisão será apresentada, abordando a evolução das técnicas e dos métodos de detecção, especialmente aqueles cujas metodologias não são protegidas por patentes.

\section{Métodos espectrofotométricos}

A aplicação dos métodos espectrofotométricos com absorção na região do ultravioleta e visível representa a classe de técnicas analíticas mais simples, de baixo custo e relativamente fáceis de serem executadas quando o objetivo é a quantificação de analitos orgânicos. A capacidade de fornecer espectros em poucos segundos de análise torna-as insubstituíveis em certos ramos da química analítica. No entanto, devido à complexidade da matriz e à falta de seletividade destas técnicas, as análises envolvendo amostras de combustíveis têm apresentado problemas de sobreposição espectral, de forma que são requeridas etapas de separação dos analitos da matriz, como também a utilização de métodos quimiométricos para discriminação das bandas de absorção. ${ }^{29}$ Percebe-se ainda que em matrizes mais complexas, como os combustíveis, além de apresentarem bandas de absorção largas e alta sobreposição espectral, as análises também são dificultadas em sistemas com multicomponentes. Portanto, para contornar os problemas decorrentes de sobreposição espectral entre analito/

Tabela 2. Dados de especificações de qualidade dos combustíveis automotivos líquidos comercializados no Brasil. Adaptada das refs. 2, 24-27

\begin{tabular}{|c|c|c|c|c|c|}
\hline \multirow{3}{*}{ Combustível } & \multicolumn{4}{|c|}{ Métodos de detecção da cor } & \multirow{3}{*}{$\begin{array}{l}\text { Quantidade adicionada } \\
\qquad\left(\mathrm{mg} \mathrm{L}^{-1}\right)\end{array}$} \\
\hline & \multicolumn{2}{|c|}{ Visual $^{\mathrm{d}}$} & \multicolumn{2}{|c|}{ Instrumental $^{\mathrm{e}}$} & \\
\hline & Norma Nacional & Norma Internacional & Norma Nacional & Norma Internacional & \\
\hline Etanol $^{\mathrm{a}}$ & NBR 7148 & ASTM D 1298 & & & 15,0 \\
\hline Gasolina & NBR 7148 & ASTM D 1298 & - & - & 50,0 \\
\hline Querosene $^{\mathrm{b}}$ & - & - & NBR 14921 & - & - \\
\hline Diesel $^{\mathrm{c}}$ & NBR 7148 & ASTM D 1298 & NBR 14483 & ASTM D 1500 & 30,0 a 40,0 \\
\hline
\end{tabular}

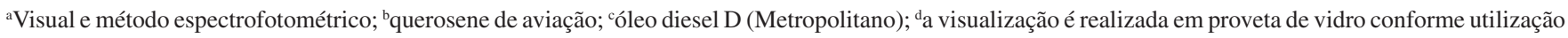
nos métodos; ${ }^{\mathrm{e}}$ métodos colorimétricos. 
interferente, são necessários métodos de extração mais eficientes, como também aplicações de cálculos matemáticos (espectroscopia derivativa) que, muitas vezes, não fornecem resultados aceitáveis. Todavia, os métodos espectrofotométricos apresentam altos limites de detecção, o que inviabiliza sua aplicação na análise de amostras contendo baixos teores do analito de interesse, principalmente, em matrizes diluídas adulteradas por outros tipos de solventes hidrocarbonetos.

O primeiro trabalho empregando a espectroscopia derivativa foi proposto por Leung e Tam, ${ }^{29}$ os quais analisaram amostras de óleo diesel industrial e determinaram o corante Solvente Vermelho 24 (SV-24). Os autores observaram que a segunda derivada do espectro de absorção do corante exibe um máximo em $555 \mathrm{~nm}$, permitindo quantificação deste analito em níveis de concentração entre 2,00 e $6,00 \mathrm{mg} \mathrm{L}^{-1}$.

Nowak ${ }^{30}$ desenvolveu um método de extração e análise espectrofotométrica para determinação quantitativa do corante Oil blue Liq. - um marcador do tipo antraquinona -, em combustível destilado do petróleo envelhecido. O método consiste na extração do analito em coluna de sílica e eluição com diclorometano ou tolueno, cuja análise permite detecção do analito na amostra em um nível de concentração da ordem de $5,00 \mathrm{mg} \mathrm{L}^{-1}$.

\section{Métodos cromatográficos}

Em meio às ferramentas que podem ser usadas para o desenvolvimento de metodologias alternativas para detecção quantitativa de corantes em amostras de combustíveis, os métodos cromatográficos, mais especificamente, a cromatografia líquida de alta eficiência (CLAE) tem sido a técnica analítica mais empregada. Esta tem se destacado das demais por possuir a vantagem de separar e quantificar um maior número de substâncias em matrizes mais complexas, o que permite obter resultados satisfatórios e confiáveis em função da possibilidade de separação destes interferentes usando uma coluna adequada, sendo o ponto de partida para análises de matrizes de grande complexidade como os derivados do petróleo.

Dentre os trabalhos encontrados, May e colaboradores ${ }^{31}$ apresentaram um método empregando a CLAE com detecção espectrofotométrica em $485 \mathrm{~nm}$, em que o sistema permite a detecção e a quantificação de resíduos de corantes - quinizarina e do Solvente Vermelho 24 - em óleo diesel após passar por um processo de lavagem para remoção do mesmo (chamado de laundered). Neste caso, o procedimento envolve uma etapa de concentração dos analitos sobre coluna pré-empacotada com sílica, na qual são separados da amostra e ao mesmo tempo concentrados na coluna, com a passagem de um maior volume de amostra. Nesta condição, o método permite a quantificação da quinizarina e do Solvente Vermelho 24 em níveis de 0,20 e $0,40 \mathrm{mg} \mathrm{L}^{-1}$, respectivamente.

Sundberg e colaboradores, ${ }^{32}$ por sua vez, desenvolveram uma metodologia analítica para análise de amostra de óleo diesel refinado e determinação do Solvente Amarelo 124, um corante marcador de uso comum entre os países da Comunidade Europeia. O método baseia-se no uso da técnica de CLAE com detecção em arranjo de diodos $(\lambda$ $=410 \mathrm{~nm}$ ) após separação em coluna de sílica, cuja análise envolve apenas diluição da amostra e posterior filtração em filtro apropriado. Obteve-se resultados satisfatórios com uso de um padrão interno (pigment yellow 3), o que permitiu detecção da ordem de $0,05 \mathrm{mg}$ $\mathrm{L}^{-1}$ do corante na amostra.

Um método semelhante foi proposto por Henricsson e Westerholm, ${ }^{33}$ no qual utilizaram a CLAE acoplada ao detector de arranjo de diodos (detecção em $420 \mathrm{~nm}$ ) para a determinação quantitativa do Solvente Amarelo 124 em amostras de óleo diesel. Neste método, os autores propõem um pré-tratamento das amostras, extraindo o corante antes de cada análise em cartuchos de extração em fase sólida contendo $500 \mathrm{mg}$ de sílica. Nesta condição, o método foi satisfatoriamente aplicado para a determinação do corante em diferentes amostras de óleo diesel, permitindo quantificação da ordem de $0,20 \mathrm{ng} \mathrm{mL}^{-1}$.

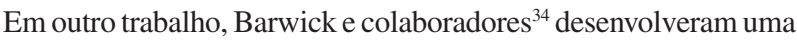
metodologia analítica para determinação de três corantes, Solvente Vermelho 24 (SV-24), quinizarina (QNZ) e Solvente Amarelo 124 (SA-124), em amostras de óleo combustível baseada na técnica de CLAE com detecção em arranjo de diodos operando entre 475 e 500 $\mathrm{nm}$. Os autores usaram dados de precisão, exatidão, recuperação e robustez para avaliarem as incertezas da metodologia utilizada, tendo como comparação amostras de referência certificadas. Após a extração dos analitos em coluna de sílica, o método pode ser aplicado com sucesso na determinação desses corantes em amostras de óleo diesel, querosene e óleo lubrificante em níveis de concentrações entre 0,041 e 4,06 $\mathrm{mg} \mathrm{L}^{-1}$ para o SV-24, 0,04 e 1,99 $\mathrm{mg} \mathrm{L}^{-1}$ para a QNZ e entre 0,04 e $4,99 \mathrm{mg} \mathrm{L}^{-1}$ para o SA-124.

Recentemente, o corante Solvente Amarelo 124 foi quantificado em amostras de gasóleo e querosene mediante uma metodologia desenvolvida por Linsinger e colaboradores, ${ }^{6}$ que empregaram a CLAE com detector espectrofotométrico operando no visível, nos comprimentos de onda de 410 e $450 \mathrm{~nm}$. A metodologia foi simples e constituiu-se da detecção direta do corante após diluição da amostra de gasóleo e querosene em hexano e posterior filtração em filtros apropriados. Este procedimento viabilizou determinar e quantificar o corante em níveis de concentração de 0,020 e 0,065 $\mathrm{mg} \mathrm{L}^{-1}$, respectivamente.

O Solvente Vermelho 26 (SV-26) também foi quantitativamente determinado empregando-se técnicas de separação antes da detecção. Neste caso, Timkovich ${ }^{35}$ propôs um método analítico utilizando a CLAE-UV-Vis e a cromatografia gasosa acoplada à espectrometria de massa para determinação e identificação do corante SV-26 em amostra de óleo diesel. $\mathrm{O}$ autor mostra que a detecção do corante foi melhorada ao ser realizada uma etapa prévia de pré-concentração baseada na retenção do analito em coluna de extração em fase sólida contendo sílica gel. Este método permitiu a detecção do corante nesta matriz em um nível de concentração da ordem de $10 \mathrm{ng} \mathrm{mL}^{-1}$.

Em um trabalho recente, ${ }^{36}$ demonstrou-se que os corantes Solvente Azul 14 (SA-14), Solvente Laranja 7 (SL-7) e Solvente Vermelho 24 (SV-24) - podem ser satisfatoriamente determinados empregando-se um sistema CLAE com detector operando na região do visível. Os corantes foram separados empregando uma coluna de fase reversa (C-18) com sistema de eluição em modo gradiente composto por acetonitrila/ $\mathrm{H}_{2} \mathrm{O}$ e vazão de $1,0 \mathrm{~mL} \mathrm{~min}^{-1}$. O método foi aplicado para determinação desses corantes em amostras de gasolina após se testarem diferentes procedimentos de extração, cujos resultados foram estatisticamente satisfatórios. O limite de detecção foi de 0,$55 ; 0,70$ e $0,85 \mathrm{mg} \mathrm{L}^{-1}$ para os corantes SL-7, SV-24 e SA-14, respectivamente.

A técnica de CLAE acoplada ao detector eletroquímico (potencial fixo em $+0,80 \mathrm{~V}$ ), também foi satisfatoriamente aplicada na quantificação dos corantes SA-14 e SV-24 em amostras de combustíveis com desempenho analítico ligeiramente superior aos detectores espectrofotométricos. Neste caso, os corantes SA-14 e SV-24 foram separados em uma coluna de fase reversa (C-18) e fase móvel acetonitrila/acetato de amônio $\left(5,0 \mathrm{mmol} \mathrm{L}^{-1}\right)$ na proporção de $90: 10(\mathrm{v} / \mathrm{v}){ }^{37}$ A quantificação em amostras de etanol combustível e querosene de aviação forneceu resultados estatisticamente aceitáveis com intervalo de recuperação entre 70 e $88 \%$. O limite de detecção estimado para este sistema foi de $0,02 \mathrm{mg} \mathrm{L}^{-1}$ para o corante SA-14 e de $0,03 \mathrm{mg}$ $\mathrm{L}^{-1}$ para o corante $\mathrm{SV}-24$.

Usando a CLAE acoplada a um sistema de detecção eletroquímico mais sofisticado, ${ }^{38}$ os corantes SA-14, SA-35, SL-7 e SV-24 foram satisfatoriamente separados em uma coluna de fase reversa (C-8) e 
Tabela 3. Resumo de métodos cromatográficos disponíveis na literatura para determinação de alguns corantes usados em combustíveis

\begin{tabular}{|c|c|c|c|c|c|c|}
\hline Corante & Matriz & Coluna & Fase Móvel & Detector & $\begin{array}{c}\mathrm{LQ} \\
\left(\mathrm{mg} \mathrm{L}^{-1}\right) \\
\end{array}$ & Ref. \\
\hline SA-124 & Gasóleo Querosene & $\begin{array}{l}\text { Si }(5 \mu \mathrm{m}) \\
250 \times 4,6 \mathrm{~mm}\end{array}$ & $\begin{array}{l}\text { Tolueno/Acetato de } \\
\text { etila }(98: 2, \mathrm{v} / \mathrm{v})\end{array}$ & $\begin{array}{l}\text { UV-Vis, } \\
\lambda=410 \mathrm{e} \\
450 \mathrm{~nm}\end{array}$ & 0,07 & 6 \\
\hline $\begin{array}{l}\text { QNZ, } \\
\text { SV-24 }\end{array}$ & Óleo diesel & $\begin{array}{l}\text { Hipersil C18 } \\
(5 \mu \mathrm{m}) \\
200 \times 4,6 \mathrm{~mm}\end{array}$ & $\begin{array}{l}\text { ACN/Formiato de amônio, } \\
\text { pH 7,6 (90:10, v/v) }\end{array}$ & $\begin{array}{l}\text { UV-Vis, } \\
\lambda=485 \mathrm{~nm}\end{array}$ & - & 31 \\
\hline SA-124 & Óleo diesel & $\begin{array}{l}\text { Nucleosil Si } \\
(5 \mu \mathrm{m}) \\
200 \times 4,6 \mathrm{~mm}\end{array}$ & Hexano/Acetato de etila (gradiente) & $\begin{array}{l}\text { DAD, } \\
\lambda=250-600 \mathrm{~nm}\end{array}$ & 0,05 & 32 \\
\hline $\begin{array}{l}\text { QNZ, } \\
\text { SV-24, } \\
\text { SA-124 }\end{array}$ & Óleo diesel Querosene & $\begin{array}{l}\text { Fenil-Hexil } \\
(5 \mu \mathrm{m}) 250 \times 4,6 \mathrm{~mm}\end{array}$ & ACN/Água (gradiente) & $\begin{array}{l}\text { DAD, } \\
\lambda=475 \text { e } 500 \mathrm{~nm}\end{array}$ & - & 34 \\
\hline SV-26 & Óleo diesel & $\begin{array}{l}\text { Partsil } \mathbf{S i}(5 \mu \mathrm{m}) \\
250 \times 4,6 \mathrm{~mm}\end{array}$ & $\begin{array}{l}\text { Hexano/clorofórmio } \\
(1: 1, v / v)\end{array}$ & $\begin{array}{l}\text { UV-Vis, } \\
\lambda=519 \mathrm{~nm}\end{array}$ & - & 35 \\
\hline SA-124 & Óleo diesel & $\begin{array}{l}\text { YMC C8 } \\
(5 \mu \mathrm{m}) \\
250 \times 4,6 \mathrm{~mm}\end{array}$ & $\begin{array}{l}\text { ACN/acetato de amônio } \\
\left(25 \mathrm{mmol} \mathrm{L}^{-1}\right), \mathrm{pH} 4,8 \\
(72: 28, \mathrm{v} / \mathrm{v})\end{array}$ & $\begin{array}{l}\text { DAD, } \\
\lambda=420 \mathrm{~nm}\end{array}$ & 0,02 & 33 \\
\hline $\begin{array}{l}\text { SA-14, } \\
\text { SL-7 e } \\
\text { SV-24 }\end{array}$ & Gasolina & $\begin{array}{l}\text { Prontosil } \\
(5 \mu \mathrm{m}) \\
120 \times 4,6 \mathrm{~mm}\end{array}$ & ACN/Água (gradiente) & $\begin{array}{l}\text { UV-Vis, } \\
\lambda=490 \text { e } 640 \mathrm{~nm}\end{array}$ & $\begin{array}{l}0,85 \\
0,55 \\
0,70\end{array}$ & 36 \\
\hline $\begin{array}{l}\text { SA-14, e } \\
\text { SV-24 }\end{array}$ & Querosene e etanol & $\begin{array}{l}\text { Phenomenex }(5 \mu \mathrm{m}) \\
250 \times 4,6 \mathrm{~mm}\end{array}$ & $\begin{array}{l}\text { ACN/acetato de amônio } \\
\left.(5 \mathrm{mmol} \mathrm{L})^{-1}\right),(90: 10, \mathrm{v} / \mathrm{v})\end{array}$ & $\begin{array}{l}\mathrm{DE}, \\
\mathrm{E}=0,80 \mathrm{~V}\end{array}$ & $\begin{array}{l}0,03 \\
0,04\end{array}$ & 37 \\
\hline $\begin{array}{l}\text { SA-14, } \\
\text { SA-35 e } \\
\text { SV-24 }\end{array}$ & Gasolina & $\begin{array}{l}\text { Knauer } \\
(5 \mu \mathrm{m}) \\
100 \times 4,6 \mathrm{~mm}\end{array}$ & $\begin{array}{l}\text { ACN/acetato de amônio } \\
\left(5 \mathrm{mmol} \mathrm{L}^{-1}\right),(75: 25, \mathrm{v} / \mathrm{v})\end{array}$ & $\begin{array}{l}\mathrm{DE} \\
\mathrm{E}=0,80 \mathrm{~V}\end{array}$ & $\begin{array}{l}0,04 \\
0,04 \\
0,04\end{array}$ & 38 \\
\hline
\end{tabular}

SA-124: Solvente Amarelo 124; SV-24: Solvente Vermelho 24; QNZ: Quinizarina; SV-26: Solvente Vermelho 26; Si: sílica; DAD: detector de arranjos de diodo; DE: Detector eletroquímico.

detectados monitorando-se a oxidação em potencial fixo de $+0,80$ V. Sob condições de eluição isocrática com fase móvel contendo uma mistura de acetonitrila e acetato de amônio $\left(5,0 \mathrm{mmol} \mathrm{L}^{-1}\right)$ na proporção de 75:25 (v/v), a metodologia foi aplicada de modo satisfatório na quantificação desses corantes em amostras de gasolina, com desempenho analítico ligeiramente superior aos detectores espectrofotométricos. Resultados analíticos aceitáveis foram obtidos, cujo limite de detecção foi da ordem de $0,04 \mathrm{mg} \mathrm{L}^{-1}$ para todos os corantes estudados, suficiente para detecção desses corantes em amostras mais diluídas do que aqueles usualmente encontrados em trabalhos reportados na literatura. ${ }^{28-35}$

A Tabela 3 apresenta um resumo com informações adicionais referentes aos métodos cromatográficos, disponíveis na literatura, desenvolvidos para quantificação de alguns corantes empregados em sistemas de marcação de combustíveis fósseis.

\section{Métodos eletroanalíticos}

A eletroanalítica é a divisão da química analítica que apresenta maior diversidade de técnicas disponíveis, sendo diversas as vantagens na determinação de compostos orgânicos, inorgânicos e organometálicos, nas mais variadas matrizes, com possibilidade de detectar o analito de interesse em solventes aquosos e não aquosos. A aplicação das técnicas eletroanalíticas convencionais na determinação de corantes pode ser relevante para a área, uma vez que esta pode atender a alguns dos requisitos para testes analíticos simples, sensíveis, econômicos e rápidos. Além disso, a eletroanalítica tem se adaptado com sucesso para atender a esta necessidade, apresentando disponibilidade de sensores eletroquímicos versáteis com capacidade de identificar e determinar os mais diversos produtos em tempo real e em concentrações a níveis baixíssimos. ${ }^{39-41}$
Estudos prévios encontrados na literatura confirmam que as técnicas eletroanalíticas são promissoras na quantificação de diversos corantes contendo grupos cromóforos, como azo e antraquinona. ${ }^{42-48} \mathrm{Os}$ resultados foram satisfatórios, uma vez que esses corantes apresentam estruturas que contêm grupos funcionais facilmente redutíveis e/ou oxidáveis. Ademais, essas matrizes são menos complexas e não oferecem tantos problemas de interferências. Esses estudos envolveram apenas classes de corantes utilizadas na indústria têxtil ou de curtume em matrizes aquosas, cuja aplicação não pode ser generalizada para classes de corantes marcadores de combustíveis, em função da alta complexidade dessas matrizes e da fraca solubilidade destes em meio aquoso. Entretanto, mesmo que a potencialidade da eletroanalítica seja notória para meio aquoso, ${ }^{42-48}$ sua aplicação na determinação de corantes em matrizes como combustíveis ainda é rara.

Em trabalhos recentes, mostrou-se que os corantes quinizarina $(\mathrm{QNZ})^{49}$ e Solvente Azul 14 (SA-14) ${ }^{50}$ podem ser quantitativamente determinados em amostras de combustíveis após, respectivamente, oxidação e redução eletroquímica sobre a superfície do eletrodo de carbono vítreo e o emprego da técnica voltamétrica de onda quadrada. Usando uma mistura contendo tampão Britton-Robinson e um solvente orgânico como eletrólito de suporte, foi possível manter a solubilidade dos corantes no meio e, consequentemente, uma melhor condição de trabalho. Após otimização das condições experimentais, observou-se que o sinal analítico obtido para QNZ e SA-14 responde linearmente em um considerável intervalo de concentração, o qual permitiu desenvolver uma metodologia simples, rápida e com sensibilidade suficiente para quantificação em níveis de $\mathrm{mg} \mathrm{L}^{-1}$. Embora as características estruturais destes corantes não sejam de natureza iônica, estes mostraram comportamento voltamétrico influenciado pela adsorção na superfície do eletrodo de trabalho quando detectados eletroquimicamente. Assim, foram necessários procedimentos alter- 
nativos de limpeza do eletrodo de trabalho por polimento mecânico, para garantir a atividade da superfície. O método proposto foi aplicado na determinação de QNZ e SA-14 em amostras de combustíveis e os resultados obtidos foram satisfatórios e concordantes, quando comparados com aqueles alcançados por métodos cromatográficos e espectrofotométricos apresentados na literatura. ${ }^{31,34}$

Os corantes Solvente Laranja 7 (SL-7) ${ }^{51}$ e Solvente Azul 14 $(\mathrm{SA}-14)^{52}$ foram eletroquimicamente detectados sobre superfície do eletrodo de carbono vítreo e de eletrodos descartáveis de carbono impresso (ECI), respectivamente, empregando meio contendo uma mistura de dimetilformamida e tampão Britton-Robinson como eletrólito suporte. No primeiro trabalho, ${ }^{51}$ mostrou-se que o corante SL-7 é oxidado $\left(\mathrm{E}_{\mathrm{p}}=+0,70 \mathrm{~V}\right.$ vs. $\left.\mathrm{Ag} / \mathrm{AgCl}\right)$ em uma mistura de tampão Britton-Robinson e $N, N$-dimetilformamida $(1: 1, \mathrm{v} / \mathrm{v})$, no qual o produto da oxidação foi fortemente adsorvido na superfície do eletrodo de trabalho, de modo que foram necessários procedimentos de limpeza da superfície por polimento mecânico - entre cada medida experimental - para evitar problemas de inativação por adsorção. Empregando a melhor condição de trabalho, um método eletroanalítico foi desenvolvido para detectar quantitativamente este corante em amostras de etanol combustível com resultados estatisticamente satisfatórios.

No segundo trabalho, ${ }^{52}$ foi mostrado que o corante SA-14 é reduzido $\left(\mathrm{E}_{\mathrm{p}}=-0,40 \mathrm{~V} v \mathrm{~s} . \mathrm{Ag} / \mathrm{AgCl}\right)$ sobre superfície de eletrodos descartáveis de carbono impresso (ECI) empregando como eletrólito suporte uma mistura de tampão Britton-Robinson e $N, N$-dimetilformamida (7:3, v/v). Para minimizar, ou até suprimir, a inativação da superfície eletródica ocasionada pela adsorção na superfície de produtos eletrogerados ou, até mesmo, do próprio reagente, empregou-se um surfactante aniônico. A utilização de surfactante para este fim viabilizou determinações eletroanalíticas, oferecendo diversas vantagens, pois manipulações externas são menos requeridas, e, quando são, exigem apenas adições na célula eletroquímica. Nesta condição, o método foi aplicado com sucesso para determinação do SA-14 em amostras de querosene e etanol combustível com recuperação média entre 82 e $99 \%$. O limite de detecção calculado para este sistema de detecção foi de $9,0 \times 10^{-8} \mathrm{~mol} \mathrm{~L}^{-1}$, ligeiramente inferior ao método espectrofotométrico desenvolvido como referência. ${ }^{52}$

Os trabalhos até aqui apresentados mostraram que a fraca solubilidade destes corantes em meio aquoso e a hidrofobicidade dessas matrizes comprometem a detecção eletroquímica desses analitos em amostras de combustíveis. Além disso, análises envolvendo técnicas eletroanalíticas em meios altamente resistivos, devido à baixa constante dielétrica de solventes orgânicos, têm se constituído como um grande obstáculo experimental a ser contornado. No caso dos eletrodos impressos, estes efeitos são mais críticos, devido à baixa resistência desses materiais a solventes orgânicos, tais como acetonitrila, dimetilformamida, acetona, etc. Outra desvantagem desses materiais eletródicos (carbono impresso) é a maior rugosidade, os quais oferecem maiores superfícies de contato com o analito e/ou produto eletrogerado, inativando-a rapidamente pelo efeito de adsorção. Entretanto, estes problemas foram satisfatoriamente contornados pelo uso de surfactantes,${ }^{53}$ o que permitiu diminuir a quantidade de solvente orgânico (acetonitrila, dimetilformamida) sem comprometer a solubilidade destes corantes no meio. Ademais, o uso de surfactantes também promoveu ampliação do sinal, deslocamento considerável do potencial de pico $\left(\mathrm{E}_{\mathrm{p}}\right)$.

Assim, as informações contidas nesta revisão, juntamente com a discussão de trabalhos envolvendo a determinação de corantes em amostras de combustíveis, servem de suporte para estudos futuros, uma vez que a produção científica nesta área tem sido praticamente inexistente.

\section{CONSIDERAÇÕES FINAIS}

Neste trabalho, foram apresentadas algumas considerações sobre marcadores e corantes usados em sistemas de marcação de combustíveis automotivos e de aviação, fornecendo informações relevantes sobre a qualidade destes produtos, bem como acerca da importância do conhecimento de algumas de suas características no desenvolvimento econômico e no impacto ambiental. Algumas características físicoquímicas também foram apontadas, as quais são fundamentalmente importantes para o desenvolvimento de métodos de pré-tratamento e análises de matrizes tão complexas como os combustíveis derivados do petróleo, visando à determinação, principalmente, de corantes utilizados como marcadores.

Uma avaliação crítica das características destes compostos e dos métodos de análises empregados demonstrou vários aspectos positivos que estimulam a geração de novos estudos com objetivo de disseminar sua aplicação com novos sistemas de detecção e separação para melhorar a performance analítica destes métodos. A diversidade de constituintes interferentes, que variam desde a origem do petróleo bruto, processo de refino até o processo de estocagem, torna ainda mais crítico os princípios básicos de escolha da técnica e dos procedimentos adotados para o desenvolvimento de métodos analíticos quantitativos.

Finalmente, as informações contidas nesta revisão devem contribuir efetivamente para o entendimento da presença de marcadores e corantes em combustíveis e, também, devem ser tomadas como base dos parâmetros de performance no desenvolvimento de metodologias analíticas que, juntamente com uma análise previa das características do detector disponível, possam elevar o grau de confiabilidade desses métodos.

\section{AGRADECIMENTOS}

Ao apoio das agências de fomento FAPESP, CAPES e CNPq.

\section{REFERÊNCIAS}

1. Chang, H. J.; Cho, G. L.; Kim, Y. D.; Energy Policy 2006, 34, 2572.

2. Agência Nacional do Petróleo, Gás Natural e Biocombustíveis; Resolução ANP n. 36, de 6 de dezembro de 2005, disponível em www. anp.gov.br, acessada em Julho 2010.

3. Agência Nacional do Petróleo, Gás Natural e Biocombustíveis; Regulamento Técnico, Portaria 274 de 1 de novembro de 2001, disponível em www.anp.gov.br, acessada em Julho 2010.

4. http://www.fecombustiveis.org.br/entendendo-a-adulteracao-decombustiveis.html, acessada em Julho 2010.

5. Environmental Protection Agency (EPA); The Oil and Gas Journal 1993, 91, 32 .

6. Linsinger, T.; Koomen, G.; Emteborg, H.; Roebben, G.; Kramer, G.; Lamberty, A.; Energy Fuels 2004, 18, 1851.

7. The hydrocarbon oil (marking) regulations 2002, disponível em http:// www.opsi.gov.uk/SI/si2002/20021773.htm, acessada em Julho 2010.

8. Orelup, R. B.; US pat. 4,735,631 1988.

9. Friswell, M. R.; Orelup, R. B.; US pat. 5,156,653 1992.

10. http://www.unitedcolor.com/petroleum.html, acessada em Julho 2010.

11. http://www.greatvistachemicals.com/dyes_and_pigments/solvent_dye. html, acessada em Julho 2010.

12. Guarantini, C. C. I.; Zanoni, M. V. B.; Quim. Nova 2000, 23, 71.

13. European Refining \& Marketing; Fuels Refining \& Marketing in Europe and The Former Soviet Union, 1, 10, 2002, disponível em http://www. process-nmr.com/pdfs/erm-v1-10-02.pdf, acessada em Agosto 2010.

14. Zadora, G.; Acta Chim. Slov. 2007, 54, 110.

15. Zollinger, H.; Color Chemistry, $2^{\text {nd }}$ ed., V. C. H. Publishers: New York, 1991. 
16. Abrahant, E. N.; Dyes and Their Intermediates, Edward Arnold: London, 1977.

17. Mühlen, C.; Zini, C. A.; Caramão, E. B.; Marriott, P. J.; Quim. Nova 2006, 29, 765.

18. Okumura, L. L.; Stradiotto, N. R.; Talanta 2007, 72, 1106.

19. Okumura, L. L.; Stradiotto, N. R.; Electroanalysis 2007, 19, 709.

20. Lanças, F. M.; Extração em fase Sólida, Ed. Rima: São Carlos, 2004.

21. Queiroz, S. C. N.; Collins, C. H.; Jardim, I. C. S. F.; Quim. Nova 2001, 24,68 .

22. Hennion, M. C.; J. Chromatogr., A 1999, 856, 54.

23. Snyder, L. R.; Kirkland, J. J.; Glajch, J. I.; Introduction to Modern Liquid Chromatography, John Wiley \& Sons: New York, 1979.

24. Agência Nacional do Petróleo, Gás Natural e Biocombustíveis; Regulamento Técnico, Portaria n. 248, de 31 de outubro de 2000, disponível em www.anp.gov.br, acessada em Julho 2010.

25. Agência Nacional do Petróleo, Gás Natural e Biocombustíveis; Regulamento Técnico, Portaria 310 de 27 de dezembro de 2001, disponível em www.anp.gov.br, acessada em Julho 2010.

26. Agência Nacional do Petróleo, Gás Natural e Biocombustíveis; Regulamento Técnico, Portaria 309, de 27 de dezembro de 2001, disponível em www.anp.gov.br, acessada em Julho 2010.

27. Agência Nacional do Petróleo, Gás Natural e Biocombustíveis; Resolução ANP n. 3, de 25 de janeiro de 2006, disponível em www.anp. gov.br, acessada em Julho 2010.

28. Harrison, B. R. B.; Heaysman, L. T.; Analyst 1961, 86, 566.

29. Leung, C. P.; Tam, S. Y. K.; Analyst 1985, 110, 883.

30. Nowak, A. V.; US pat. 5,304,493 1994.

31. May, E. M.; Hunt, D. C.; Holcombe, D. G.; Analyst 1986, 111, 993.

32. Sundberg, L. N.; Andrasko, J.; Wistedt, I.; Kopp, I.; J. Foren. Scienc. 1996, 41,300 .

33. Henricsson, S.; Westerholm, R.; J. Chromatogr., A 1996, 723, 395.

34. Barwick, V. J.; Ellison, S. L. R.; Rafferty, M. J. Q.; Gill, R. S.; Accred. Qual. Assur. 2000, 5, 104.
35. Timkovich, R.; Dyes Pigm. 2000, 46, 69.

36. Trindade, M. A. G.; Zanoni, M. V. B.; Matysik, F-M.; Fuel 2006, 89, 2463.

37. Trindade, M. A. G.; Rinaldo, D.; Vilegas, W.; Zanoni, M. V. B.; Quim. Nova 2007, 33, 146.

38. Trindade, M. A. G.; Zanoni, M. V. B.; Matysik, F-M.; Electroanalysis 2010, 22, 955 .

39. Osteryoung, J.; O’Dea, J. J. Em Electroanalytical chemistry; Bard, A. J., ed.; Marcel Dekker: New York, 1986, cap. 14.

40. Nascimento, V. B.; Angnes, L. A.; Quim. Nova 1998, 21, 614.

41. Hart, J. P.; Wring, S. A.; Trends Anal. Chem. 1997, 16, 89.

42. Zanoni, M. V. B.; Carneiro, P. A;. Furlan, M.; Guaratini, C. C. I.; Fogg, A. G.; Anal. Chim. Acta 1999, 385, 385.

43. Zanoni, M. V. B.; Fogg, A. G.; Barek, J.; Zima, J.; Anal. Chim. Acta 1995, 315, 41

44. Zanoni, M. V. B.; Fogg, A. G.; Barek, J.; Zima, J.; Anal. Chim. Acta 1997, 349, 101 .

45. Guaratini, C. C. I.; Fogg, A. G.; Zanoni, M. V. B.; Dyes Pigm. 2001, 50, 211.

46. Guaratini, C. C. I.; Fogg, A. G.; Zanoni, M. V. B.; Electroanalysis 2001, 13,1535 .

47. Guaratini, C. C. I.; Fogg, A. G.; Zanoni, M. V. B.; Microchem. J. 2002 , 71,65 .

48. Zanoni, M. V. B.; Souza, W. R.; Lima, J. P.; Carneiro, P. A.; Fogg, A. G.; Dyes Pigm. 2006, 68, 19.

49. Trindade, M. A. G.; Ferreira, V. S.; Zanoni, M. V. B.; Dyes Pigm. 2006, $74,566$.

50. Trindade, M. A. G.; Zanoni, M. V. B.; Electroanalysis 2007, 19, 1901.

51. Romanini, D. C.; Trindade, M. A. G.; Zanoni, M. V. B.; Fuel 2009, 88, 105.

52. Trindade, M. A. G.; Zanoni, M. V. B.; Sens. Actuators, B 2009, 138, 257.

53. Trindade, M. A. G.; Tese de Doutorado, Universidade Estadual Paulista, Brasil, 2009. 